\title{
Erratum zu: Mitarbeiterorientierte Gestaltung des unternehmensinternen Wissenstransfers
}

Kirsten A. Schröder

Der Autorenname war in allen Kapiteln dieses Buches falsch erfasst. Der richtige Autorenname sollte Kirsten A. Schröder sein. Dies wurde korrigiert.

Die aktualisierte Online-Version des Buchs finden Sie unter https://doi.org/10.1007/978-3-322-81576-7.

K. A. Schröder, Mitarbeiterorientierte Gestaltung des unternehmensinternen Wissenstransfers, DOI 10.1007/978-3-322-81576-7,

(C) Deutscher Universitäts-Verlag/GWV Fachverlage GmbH, Wiesbaden, 2019 